\title{
Color removal from industrial wastewater with a novel coagulant flocculant formulation
}

\author{
${ }^{1 *}$ M. S. Rahbar, ${ }^{2}$ E. Alipour and ${ }^{3}$ R. E. Sedighi \\ ${ }^{1}$ Department of Chemical engineering, Imam Hussein University, Tehran, Iran \\ ${ }^{2}$ Department of Chemistry, Islamic Azad University, North Tehran Branch, Tehran, Iran \\ ${ }^{3}$ Department of Applied Chemistry, Islamic Azad University, North Tehran Branch, Tehran, Iran
}

Received 16 November 2005; $\quad$ revised 6 February 2006; $\quad$ accepted 25 February $2006 \quad$ available online 18 April 2006

\begin{abstract}
Chemically enhanced wastewater treatment is attracting substantial interest among the currently employed chemical unit processes in wastewater treatment. Coagulation-flocculation has received considerable attention for yielding high pollutant removal, especially color removal. This investigation presents a novel formulation of coagulation-flocculation for color removal from industrial wastewater and illustrates its efficiency, with aid of measurement of solid sludge content, suspended solid content, percentage of solid recovery, UV absorption in wastewater effluent from two automotive factories. The results show that the novel formulation can remove color content from wastewater efficiently. The treated wastewater had UV absorption close to distillated water and color was removed up to $96 \%$ by flocculation / coagulation treatment.
\end{abstract}

Key words: Coagulation, flocculation, jar test, painting unit, wastewater, color removal

*Corresponding Author, E-mail: msmnani@mail.ihu.ac.ir

\section{INTRODUCTION}

Wastewaters contain particles with a wide variety of shapes, sizes, densities, etc, which influence their behavior in water and, therefore, their capacity to be removed. In industrial wastewater, the advanced treatment of color removal such as chemical coagulation may be used as pretreatment in order to enhance the biodegradability of wastewater during the biological treatments. A concentrated sludge may contain $10^{5} \mathrm{mg} /$ L (10\%) or more suspended solids; an untreated wastewater $100-1000 \mathrm{mg} / \mathrm{L}(0.01-0.1 \%)$; a treated wastewater $3-30 \mathrm{mg} / \mathrm{L}$ (0.0003-0.003\%); a potable water less than $0.1 \mathrm{mg} / \mathrm{L}(0.00001 \%)$. These suspended particles are ordinarily polydisperse (range of different sizes), are nonspherical (fibers, irregular grains, amorphous shapes), and have variable densities (greater or less than that of water). The four class designations and the applicable size ranges of suspended particles listed in Table 1 (McKetta, 2004). The removal of particles and organic matter from wastewater is often achieved by coagulation, usually performed with iron or aluminum salts. Coagulation can be interpreted as the conversion of colloidal and dispersal particles into small visible floc upon addition of a simple electrolyte. Increasing the concentration of the electrolyte results in a compression of the electrical double layer surrounding each suspended particle, a decrease in the magnitude of the repulsive interactions between particles and destabilization of the particles. The most common coagulant used in wastewater treatment is alum $\mathrm{Al}_{2}\left(\mathrm{SO}_{4}\right)_{3} \cdot 4 \mathrm{H}_{2} \mathrm{O}$ and $\mathrm{PAC}$ (polyaluminum chloride), due to its effectiveness in treating a wide range of wastewater type and relatively low cost. Inorganic coagulants are simple electrolytes which are water-soluble, low-molecular weight acids, bases, or salts. Various inorganic coagulants are listed in Table 2.

The use of performed polymerized forms of $\mathrm{Al}$ has become more common as alternative coagulants, such as polyaluminum chloride and polyaluminum sulphate. These coagulants have the advantage of being more effective at lower temperatures and a boarder $\mathrm{pH}$ range than alum (Exall and Vanloon, 2003). Additionally, the higher charge density of polyaluminum chloride species often results in a decrease in the coagulant dose and the associated solids production. Alum, PAC and sodium aluminate function as a coagulant by initially forming positively charged $\mathrm{Al}$ species that adsorb to negatively charged natural particles resulting in charge neutralization. These species are thought to be primarily 
Table 1: Relative sizes of suspended particles

\begin{tabular}{ll}
\hline Class & Diameter $(\mathrm{mm})$ \\
\hline Colloidal & $0.000001-0.001$ \\
Dispersed & $0.001-0.1$ \\
Coagulated & $0.1-1.0$ \\
Flocculated & $1.0-10.0$ \\
\hline
\end{tabular}

Table 2: Inorganic coagulants

\begin{tabular}{ll}
\hline Chemical name & Formula \\
\hline Salts: & \\
Aluminum chloride & $\mathrm{AlCl}_{3}$ \\
Aluminum sulfate & $\mathrm{Al}_{2}\left(\mathrm{SO}_{4}\right)_{3}$ \\
Calcium chloride & $\mathrm{CaCl}_{2}$ \\
Calcium oxide & $\mathrm{CaO}$ \\
Ferrous chloride & $\mathrm{FeCl}_{2}$ \\
Ferric chloride & $\mathrm{FeCl}_{3}$ \\
Ferrous sulfate & $\mathrm{FeSO}_{4}$ \\
Ferric sulfate & $\mathrm{Fe}_{2}\left(\mathrm{SO}_{4}\right)_{3}$ \\
Sodium aluminate & $\mathrm{NaAlO}_{2}$ \\
Acids: & \\
Hydrochloric acid & $\mathrm{HCl}_{\text {Sulfuric acid }}$ \\
Bases: & $\mathrm{H}_{2} \mathrm{SO}_{4}$ \\
Calcium hydroxide & \\
Sodium hydroxide & $\mathrm{Ca}(\mathrm{OH})_{2}$ \\
\hline
\end{tabular}

In most cases, the aluminum hydroxide sols are formed so rapidly (1-2 sec). These amorphous solid species are responsible for the charge neutralization of natural particles also contribute to the formation of larger floc (Delgado, et al., 2003). Aggregates formed predominantly by bridging of particles with a coagulant or polymer partially recover after shearing to a steady state floc size, whereas when charge neutralization is the dominant aggregation mechanism, there is a higher degree of recovery. Generally as aggregate size increases in natural water using $\mathrm{Al}$ based coagulants, fractal dimension decreases. Under typical wastewater treatment conditions particles are unable to penetrate the interior of aggregates and tend to attach on the exterior, which forms a more open, less dense structure. However, it has also been proposed that increasing aggregate size may correspond to increasing fractal dimensions as a result of break up and reaggregation of larger aggregates into denser, more compact structure (McCurdy et al., 2004).

Flocculation is usually interpreted as the further agglomeration of slowly-settling coagulated particles into large rapidly-settling (or floating) floc upon the addition of an organic polyelectrolyte. Flocculant molecules attach and bridge between particles to form larger agglomerates. Some characteristic properties of different type of polyacrylamide (PAM) as flocculant agent are given in Table 3 (Bersa et al., 2004). Polyelectrolyte flocculants are linear or branch chain organic polymers which form complex ions in solution. Polyelectrolytes have high molecular weights and are fully water-soluble. Various types of polyelectrolyte flocculants are listed in Table 4 (Heimer, 2004).

Table 3: Characteristic properties of different type of polyacrylamide (PAM)

\begin{tabular}{lccc}
\hline \multicolumn{1}{c}{ Ionic type } & M.W (g/mol) & Charge density $(\mathrm{C} / \mathrm{g})$ & $\begin{array}{c}\text { Percentage charge } \\
\text { monomer }\end{array}$ \\
\hline Anionic PAM & $5.5-7 \times 10^{6}$ & -260 & 30.0 \\
Cationic PAM & $6.0-7 \times 10^{6}$ & +150 & 19.0 \\
Non-ionic PAM & $5.0 \times 10^{6}$ & -1.07 & - \\
\hline
\end{tabular}

Table 4: Polyelectrolyte flocculants

\begin{tabular}{|c|c|c|}
\hline Type & Ionic charge & Examples \\
\hline \multirow[t]{5}{*}{ Anionic } & Negative & Poly(acrylamide), partially hydrolyzed (>5-40\%) \\
\hline & & Poly(acrylic acid) and salts \\
\hline & & Poly(acrylamide/acrylic acid) copolymers \\
\hline & & Poly(styrene sulfonic acid) and salts \\
\hline & & Poly(vinyl alcohol) \\
\hline \multirow[t]{5}{*}{ Cationic } & Positive & Poly(alkylene polyamine) \\
\hline & & Poly(epichlorohydrin) \\
\hline & & Poly(ethylenimine) \\
\hline & & Poly(dimethyl aminomethylacrylamide) \\
\hline & & Poly(diallyldimethyl ammonium chloride) \\
\hline Nonionic & Neutral & Poly(acrylamide), partially hydrolyzed (<1-5\%) \\
\hline Miscellaneous & Variable & $\begin{array}{l}\text { Alginic acid, Cellulose, Dextron, Glues, Gums, Starch, Other } \\
\text { natural products and derivatives }\end{array}$ \\
\hline
\end{tabular}


The presence of organic matter generally increases the required coagulant dosage. It has been suggested that Al hydrolysis products from insoluble aluminumhumates or -fulvates with humic substances, producing a colloidal sol that settles very slowly. At higher coagulant doses, the aluminum-organic complexes may be removed by incorporation into $\mathrm{Al}(\mathrm{OH})_{3}$ flocs (Aguilar et al., 2003).

Bach and Papavasilopouls draw together information on factors which influence the conditioning and dewatering behavior of on alum sludge gained from the coagulation of low-turbidity colored water. In their research, they focused on potential impact of aluminum hydroxide on the sludge character. They found that, there were strong similarities in the behavior of different solution, indicating the potential impact of the hydroxide. They showed also, that, there were common features being displayed by both the organic fractions and the hydroxide. They studied effects of $\mathrm{pH}$ and alum concentration in color removal as described in Fig.1 (Bache and Papavasilopoulos, 2003). Duan and Gregory investigated on coagulation by hydrolyzing aluminum and iron salts and their dependence on $\mathrm{pH}$ and coagulant dosage. They illustrated the hydrolysis constants for successive deprotonations in terns of following equations.

$$
\begin{aligned}
& \mathrm{Me}^{3+}+\mathrm{H}_{2} \mathrm{O} \rightleftarrows \mathrm{Me}(\mathrm{OH})^{2+}+\mathrm{H}^{+} \mathrm{K}_{1} \\
& \mathrm{Me}+(\mathrm{OH})^{2+}+\mathrm{H}_{2} \mathrm{O} \rightleftarrows \mathrm{Me}(\mathrm{OH})_{2}^{+}+\mathrm{H}^{+} \mathrm{K}_{2} \\
& \mathrm{Me}+(\mathrm{OH})_{2}^{+}+\mathrm{H}_{2} \mathrm{O} \rightleftarrows \mathrm{Me}(\mathrm{OH})_{3}+\mathrm{H}^{+} \mathrm{K}_{3} \\
& \mathrm{Me}+(\mathrm{OH})_{3}+\mathrm{H}_{2} \mathrm{O} \rightleftarrows \mathrm{Me}(\mathrm{OH})_{4}^{-}+\mathrm{H}^{+} \mathrm{K}_{4}
\end{aligned}
$$

And for solubility constant:

$\mathrm{Me}(\mathrm{OH})_{3} \rightleftarrows \mathrm{Me}^{+3}+3 \mathrm{OHK}_{2}$

Table 5 gives the hydrolysis and solubility constants for aluminum and iron at $25^{\circ} \mathrm{C}$ (Duan and Gregory, 2003). But, for practical purpose, product of monomeric hydrolysis of $\mathrm{Fe}(\mathrm{III})$ and $\mathrm{Al}(\mathrm{III})$ can be presented as Fig. 1. Kan, Huang and Pan employed a photometric dispersion analyzer (PDA) to monitor clay coagulation by alum and polymeric aluminum chloride (PAC).

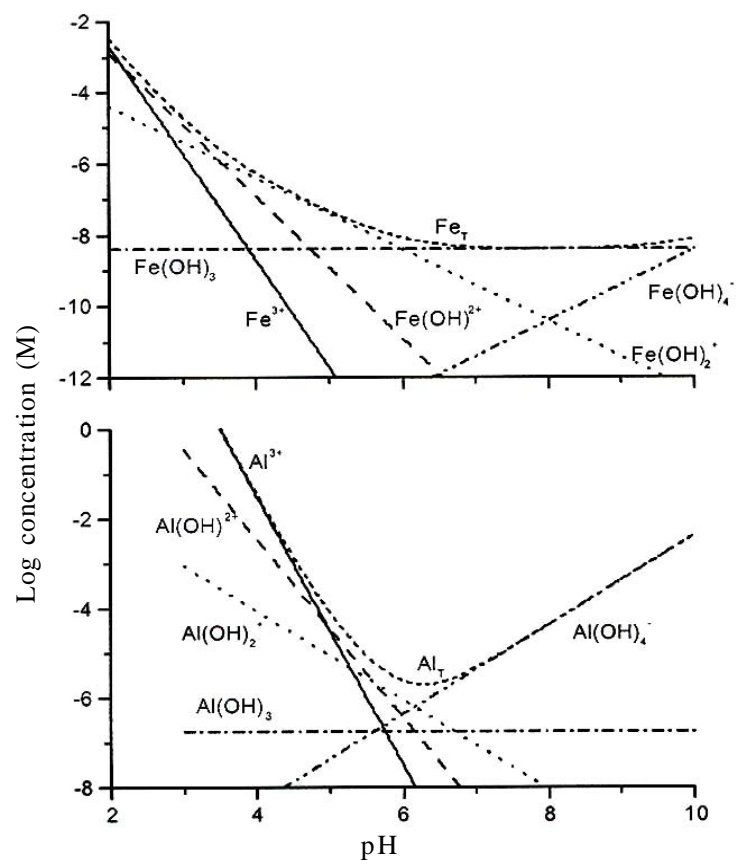

Fig. 1: Concentration of monomeric hydrolysis products of $\mathrm{Fe}$ and $\mathrm{Al}$ in equilibrium with the amorphous hydroxides at zero ionic strength and $25^{\circ} \mathrm{C}$.

They studied the effect of rapid mixing time on particle removal. They proposed adequate mixing times by PDA and mixing test methods (Kan et al., 2002).

Larsson, Walldal and Wall investigated the flocculation of large cationic polymers and nanosized particles. They found that the molecular architecture of the polymer (linear or branched) is essential for the flocculation behavior. Only in the case of the linear polymer, the degree of aggregation of the particle is important (Larsson et al., 1999).

Liu and Liang studied the effect of recirculation of chemical sludge and integrated sludge on enhancement of color removal in integrally industrial wastewater plant. They showed that with sludge recirculation the process of coagulation for the color removal has up to $35 \%$ enhancement in comparison with no sludge recirculation (Liu and Liang, 2004). Delgado, Diaz, Garcia and Otero compared effectiveness of three inorganic coagulants-aluminum sulphate, ferric chloride and polyaluminum chloride (PAC)- in reducing

Table 5: the hydrolysis and solubility constants for aluminum and iron at $25{ }^{\circ} \mathrm{C}$

\begin{tabular}{cccccc}
\hline & $\mathrm{K}_{1}$ & $\mathrm{~K}_{2}$ & $\mathrm{~K}_{3}$ & $\mathrm{~K}_{4}$ & $\mathrm{~K}_{5}$ \\
\hline $\mathrm{Al}^{3+}$ & 4.95 & 5.6 & 6.7 & 5.6 & 31.5 \\
$\mathrm{Fe}^{3+}$ & 2.2 & 3.5 & 6 & 10 & 38 \\
\hline
\end{tabular}


the turbidity of secondary effluents from a conventional wastewater treatment plant. They showed that the optimal conditions are $50 \mathrm{mg} / \mathrm{L}$ corresponded to $\mathrm{pH}=6$ and a dose of PAC of $20 \mathrm{mg} /$ $\mathrm{L}$, but the recommended conditions are $50 \mathrm{mg} / \mathrm{L}$ for $\mathrm{pH}=6$ to obtain a turbidity reduction of $90 \%$ (Delgado et al., 2003). In present investigation, a novel formulation of coagulant/flocculant has been introduced and treated on effluent of two automotive factories. The concentration of color in the effluent wastewater was up to $5 \mathrm{~g} / \mathrm{L}$. The efficiency of color removal from the wastewater as floated sludge was evaluated by determination of suspended solid content, sludge solid content, solid recovery percentage and UV absorption of treated wastewater. This research carried out in chemistry department of Islamic Azad University, north branch with cooperating of Iran Khodro and Mehrkam Pars companies.

\section{MATERIALSAND METHODS}

The wastewater samples were obtained from painting unit of two Iranian vehicle-manufacturing companies, Iran Khodro and Mehrkam Pars. For better comparison, three samples of each wastewater tank were taken for treatment.

In this investigation, a novel formulation as powder, which consists of coagulant, flocculant, coagulant aid and $\mathrm{pH}$ adjusters, have been applied for color removal from industrial wastewater. The formulation has been treated to the wastewater taken from sludge reservoir of two grand automobile painting units. The ingredients of coagulant / flocculants formulation are listed in table 6 in weight percentages.

Table 6: Ingredients of coagulant / flocculant formulation

\begin{tabular}{llc}
\hline \multicolumn{1}{c}{ Role } & \multicolumn{1}{c}{ Component } & wt \% \\
\hline pH adjuster & $\mathrm{KOH}$ & 8 \\
coagulant & $\mathrm{PAC}$ & 37 \\
coagulant & $\mathrm{NaAlO}_{2}$ & 40 \\
coagulant & $\mathrm{Na}_{2} \mathrm{SiO}_{3}$ & 4 \\
pH adjuster & $\mathrm{Na}_{2} \mathrm{CO}_{3}$ & 4 \\
coagulant aid & Polyvinyl alcohol & 6 \\
flocculant & PAM & 1 \\
\hline
\end{tabular}

Each component in the formulation has the specific character, which permits to have more efficiency in color removal. Their roles can be gathered in four classifications as below:

- Coagulants: Polyaluminum chloride (PAC), sodium aluminate $\left(\mathrm{NaAlO}_{2}\right)$ and sodium silicate are poly electrolyte materials and play the role of coagulant. PAC is a polymer which has low molecular weight, high charge density and short chain length.

- Flocculant: Polyacryl amide (PAM), has long chain length, low charge density and high bonding ability.

- Coagulant aid: Polyvinyl alcohol with long chain length that permits air penetration into molecules and increasing of flocculation action.

- pH adjusters: Potassium hydroxide and sodium carbonate have the role of $\mathrm{pH}$ adjuster for maintaining $\mathrm{pH}$ of solution in range of about $8.5-10$.

The operation condition and speed of stirring during the each step are presented in Table 7.

\section{Treatment method}

The specifications of the wastewater treatment tanks are presented in Table 8 and Fig. 2. The settling time for each experiment was $2 \mathrm{~h}$. For evaluation of efficiency of formulation in color removal, three samples of $1 \mathrm{~L}$ of treated wastewater in $1 \mathrm{~m}$ depth of vessel were taken.

Then, sludge solid content can be calculated using the following formula:

Sludge solid $=\frac{z-x}{y-x}$

that:

$x=$ weight of the container in grams

$y=$ weight of the container and sludge in grams

$\mathrm{Z}=$ weight of the container and sludge after $2 \mathrm{hr}$ at

$105^{\circ} \mathrm{C}$ in oven

with considering that total solid which exists initially in the solution:

$C=$ color + coagulant $/$ flocculant material

Thus, the suspended solid in solution and solid recovery percentage are calculated as:

Suspended solid $=C-$ sludge solid content

$\%$ solid recovery $=\frac{\text { sludge solid content }}{C} \times 100$ 
Table 7: operational conditions for different formulations used

\begin{tabular}{lc}
\hline Agitation speed in coagulation/flocculation step (rpm) & 400 \\
Time of coagulation/flocculation step (sec.) & 900 \\
Agitation speed of Settling (rpm) & 200 \\
Settling time (sec) & 90 \\
\hline
\end{tabular}

Table 8: The specification of Iran Khodro and Mehrkam Pars wastewater treatment tanks

\begin{tabular}{cccccc}
\hline & Volume $\left(\mathrm{m}^{3}\right)$ & Height $(\mathrm{m})$ & $\begin{array}{c}\text { The value of } \\
\text { primary color }(\mathrm{kg})\end{array}$ & $\begin{array}{c}\text { The value of powder that added } \\
\text { to the tank }(\mathrm{kg})\end{array}$ & Impeller type \\
\hline $\begin{array}{c}\text { Iran Khodro } \\
\begin{array}{c}\text { Mehr } \\
\text { Kam Pars }\end{array}\end{array}$ & 150 & 5 & 5 & 150 & Turbine \\
\hline
\end{tabular}

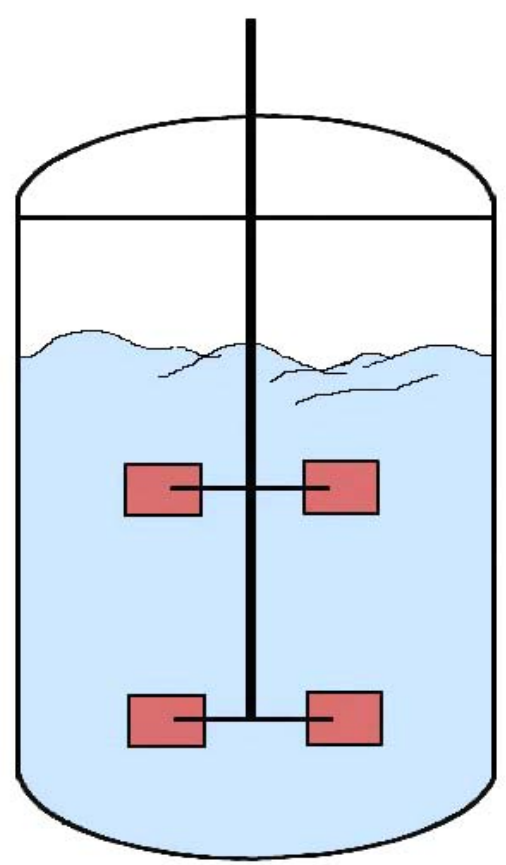

Fig. 2: Wastewater treatment tank

\section{Treatment method}

The specifications of the wastewater treatment tanks are presented in Table 8 and Fig. 2. The settling time for each experiment was $2 \mathrm{~h}$.

\section{RESULTS}

Figs. 3, 4 and 5 show the sludge, suspended solid contents and the solid recovery percentages for three samples obtained from IranKhodro. Figs. 6, 7 and 8 also, present the results for three samples obtained from Mehrkam Pars and show the high efficiency of treatment in separation of solids. Ultra Violet absorptions of solution after treatment for all of samples are presented in Figs. 9 and 10.

\section{DISCUSSION AND CONCLUSION}

The results of the sludge, suspended solid content and the solid recovery percentages for there samples obtained from Inrankhodro and Mehrkam Pars (Figs. 3 to 8) illustrate that treatment of coagulant/ flocculant has the similar efficiency for all of samples (with maximum $0.1 \%$ difference among results) and separates their solid contents very well. The amounts of absorption of the solution (Figs. 9 and 10) for different samples are close to absorption of distillated water. That means the treated wastewaters have the behavior of distillated water in point of view of UV absorption. In explaining of the results, it must be mentioned that aluminum ions are released in wastewater by PAC and sodium aluminate which surrounds the color and neutralizes it as shown in Fig. 11. Sodium silicate enhances this action. Then, the coagulated particles flocculate by chain S of PAM and float toward free surface of wastewater (Fig. 12). Polyvinyl alcohol as coagulant aid agent produces air bubbles among physical bandings (hydrogen bonds) and therefore, reinforces the floatation of color as sludge (Fig. 13). Entire results show that, the novel composition of the coagulant / flocculant can separate the color from industrial wastewater concentration up to $5 \mathrm{~g} / \mathrm{L}$. After addition of coagulant / flocculant composition to wastewater treatment tanks, PAC and sodium aluminate neutralize the color and PAM flocculate it. The sludge, which is produced within treatment, is floated by polyvinyl alcohol and removed. By this composition, the color can be separated up to $96 \%$ from industrial wastewater. The industrial wastewaters after treatment with coagulant / flocculant composition have UV absorption close to absorption of distillated water. 
M. S. Rahbar, et al.

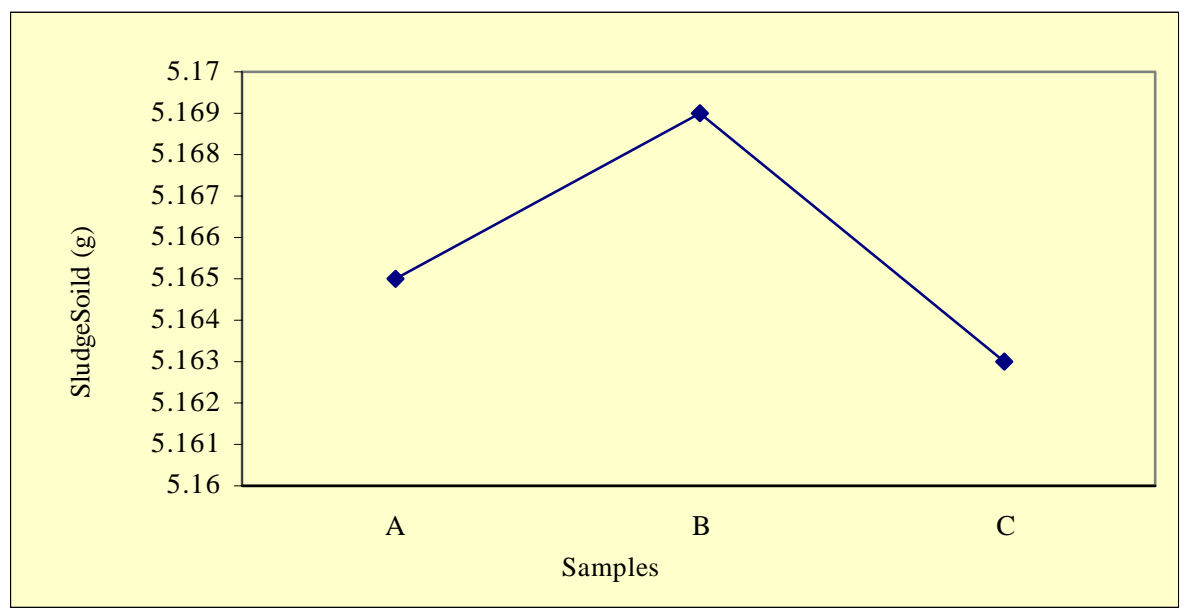

Fig. 3: Sludge solid content for different samples obtained from Iran Khodro Co.

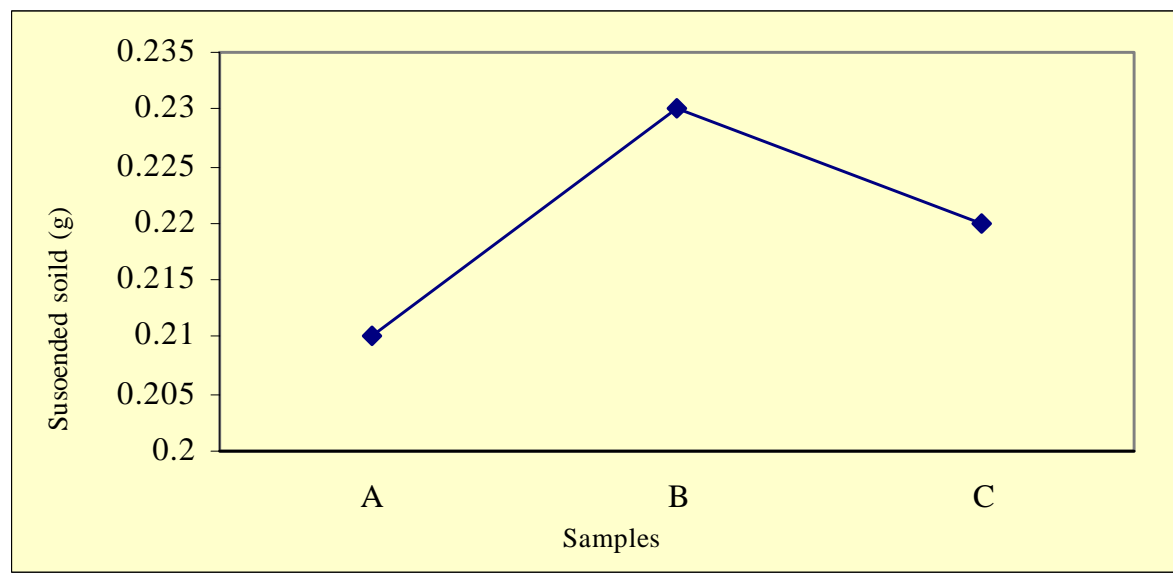

Fig. 4: Suspended solid content for different samples obtained from Iran Khodro Co.

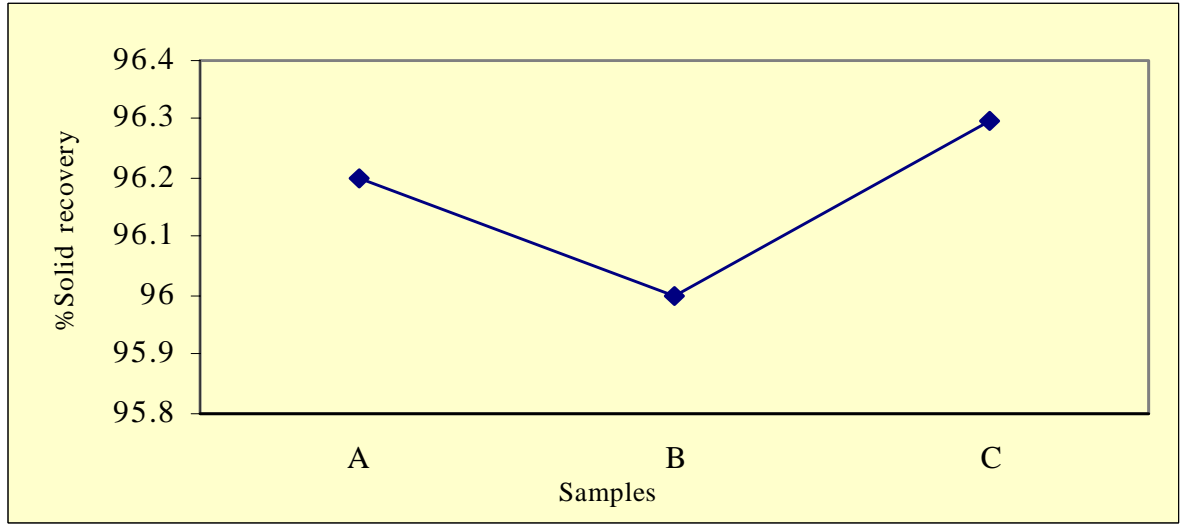

Fig. 5: \%Solid recovery for different samples obtained from Iran Khodro Co. 
Color removal from...

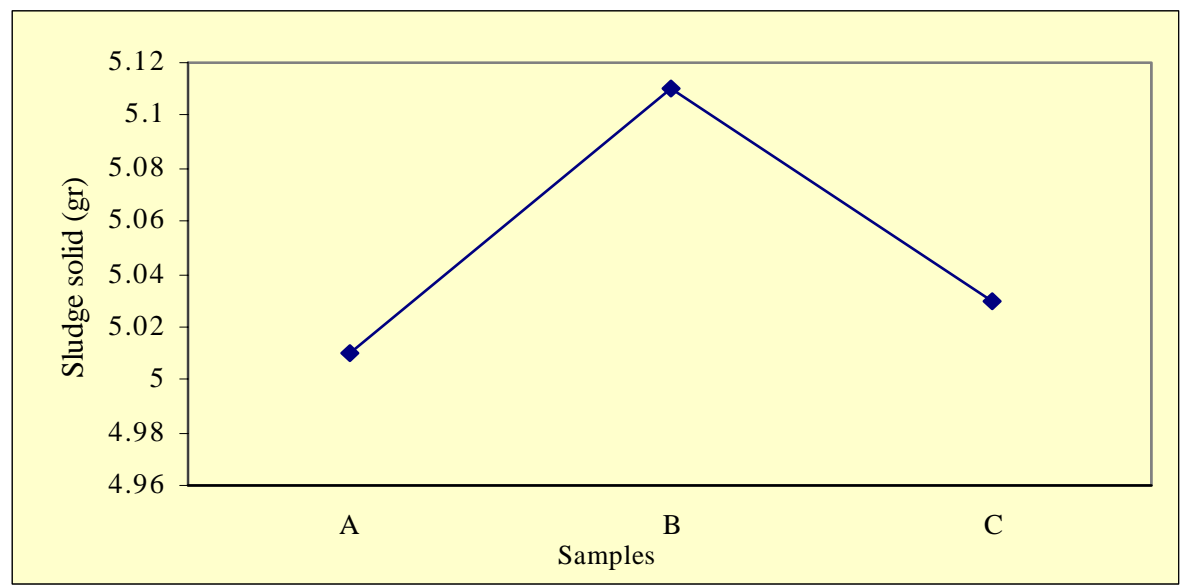

Fig. 6: Sludge solid content for different samples obtained from Mehrcam Pars Co.

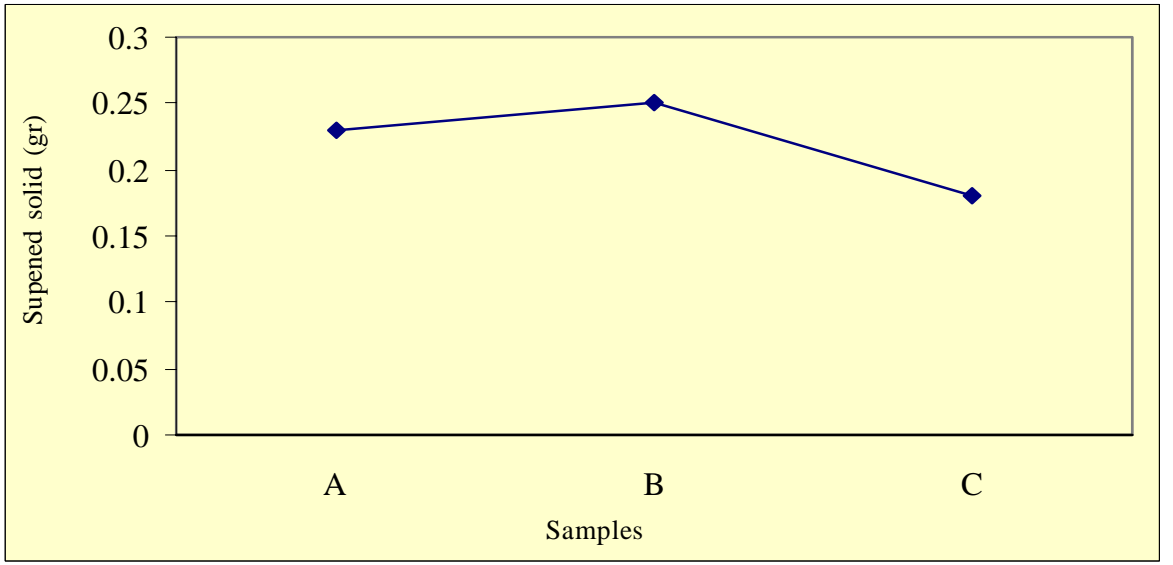

Fig. 7: Suspended solid content for different samples obtained from Mehrcam Pars Co.

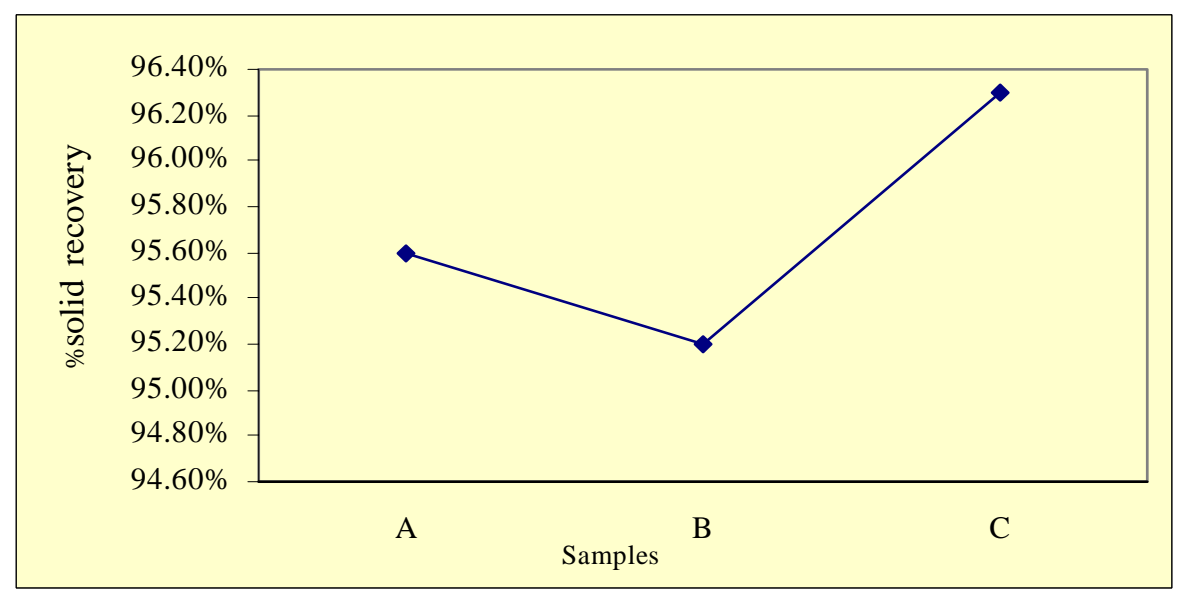

Fig. 8: \% Solid revocery for different samples obtained from Mehrcam Pars Co. 
M. S. Rahbar, et al.

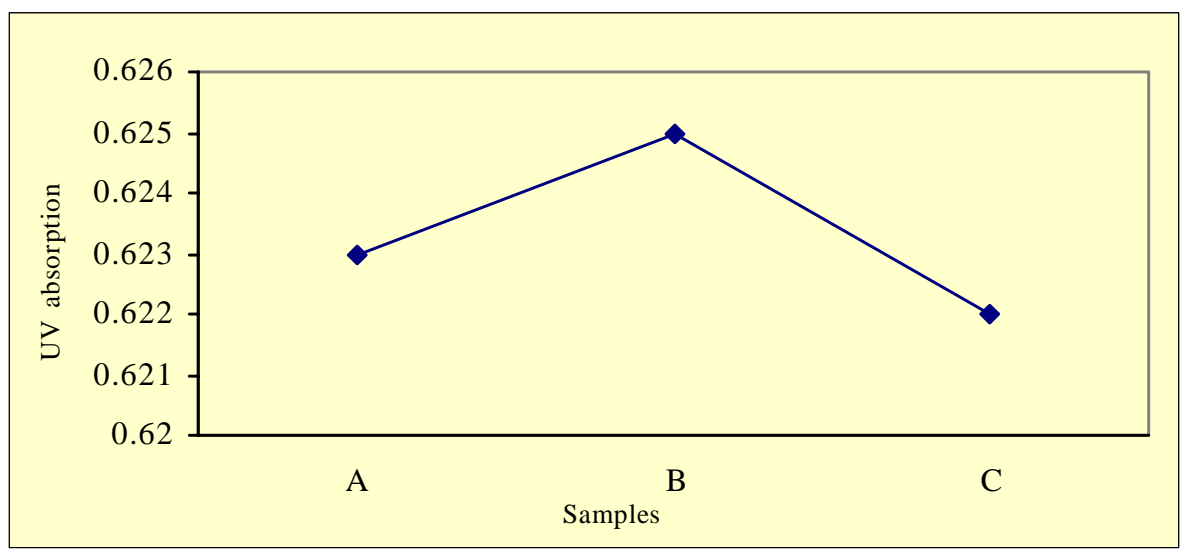

Fig. 9: UV absorption for different samples obtained from Iran Khodro Co.

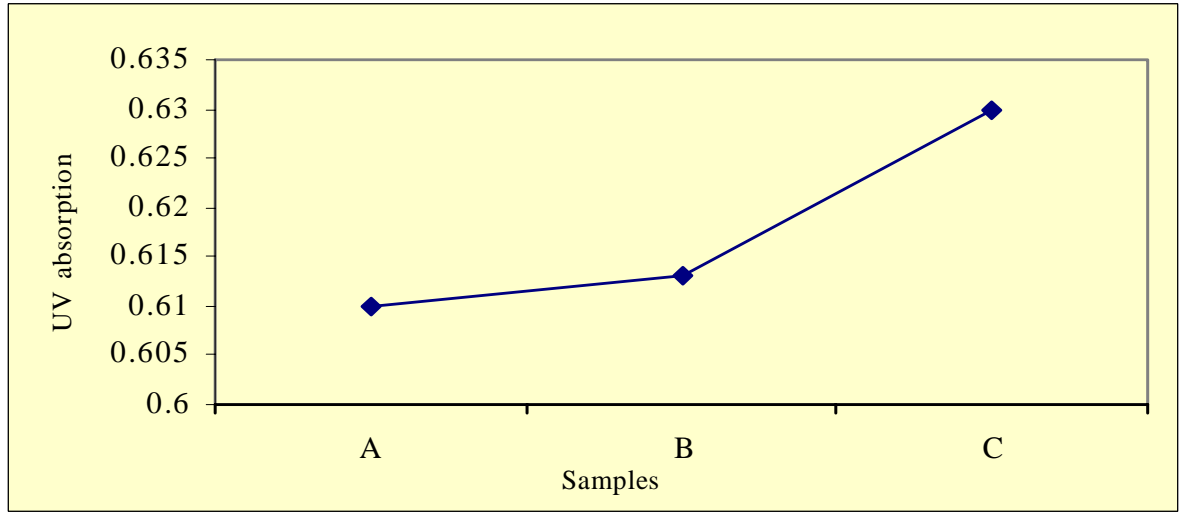

Fig. 10: UV absorption for different samples obtained from Mehrcam Pars Co.

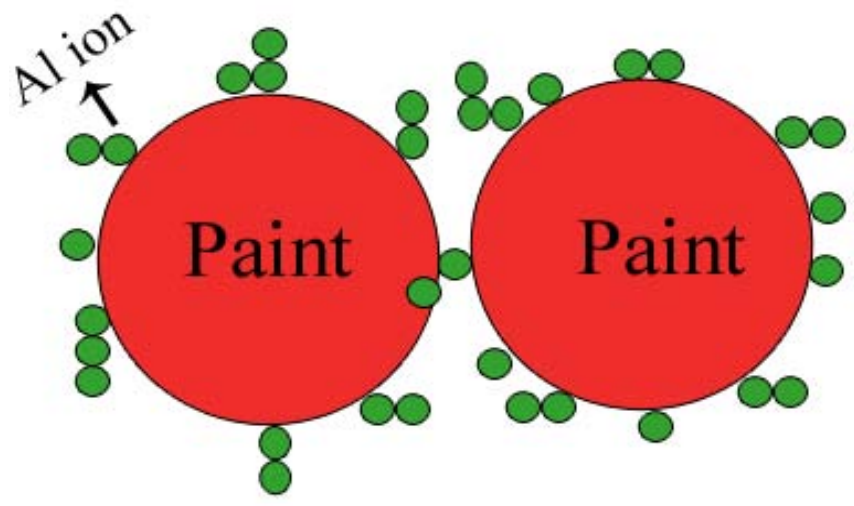

Fig. 11: Deposition of metal hydroxide species on oppositely-charged particles, showing charge neutralization 


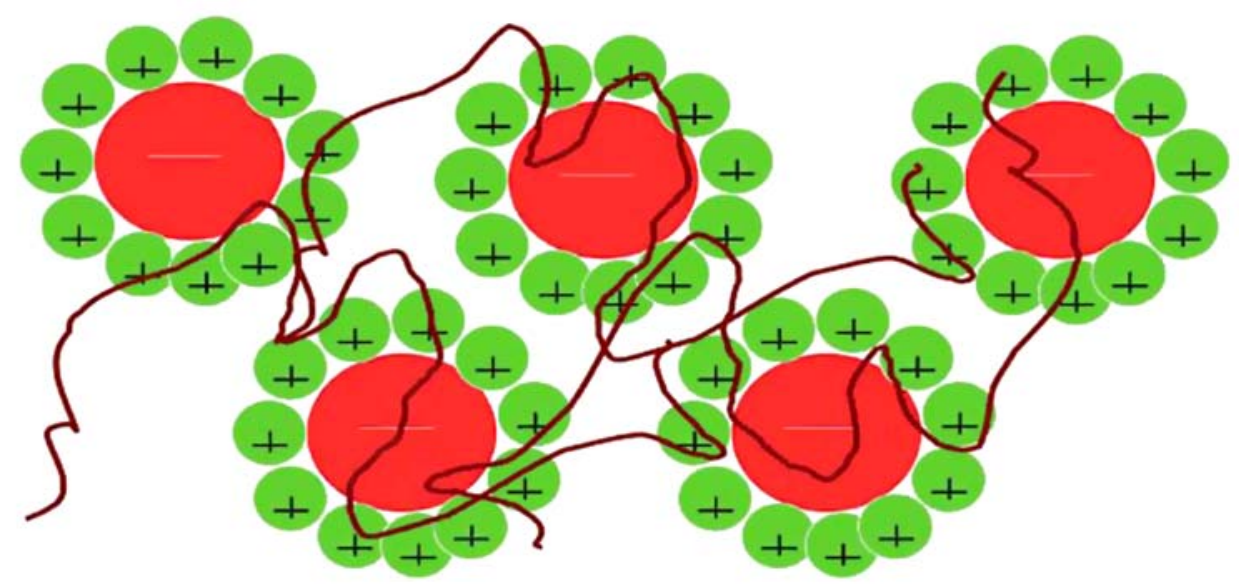

Fig. 12: Mechanism of paint flocculation

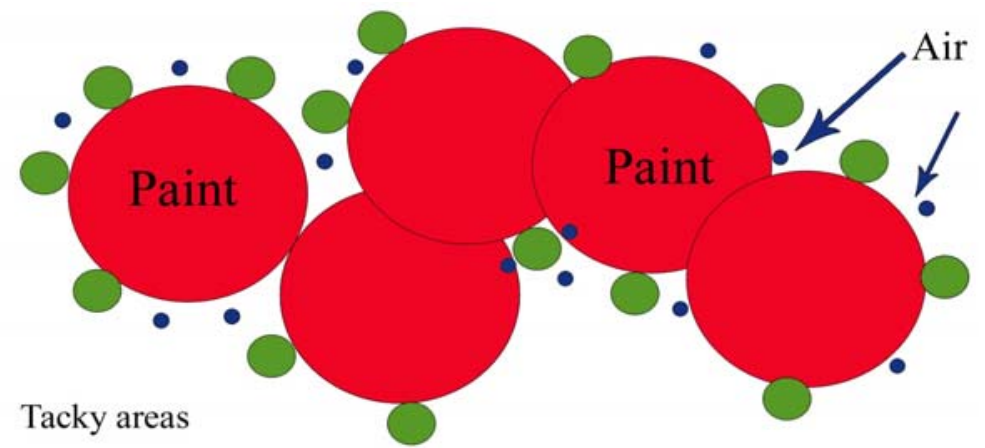

Fig. 13: Mechanism of paint floatation (as sludge) by coagulant aid

\section{REFERENCES}

Aguilar, I. M., Saez, J., Liorens, M., Soler, A. and Ortuno F. G., (2003)., Microscopic observation of particle reduction in slaughterhouse wastewater by coagulation-flocculation using ferric sulfate as coagulant and different coagulant aids. Wat. research, 37, 2233-2241.

Bache, H. D. and Papavasilopoulos, N. E., (2003)., Dewatering of alumino-humic sludge: impacts of hydroxide, Wat. Research, 37, 3289-3298.

Bersa, L., Sengupta, K. D., Poy, K. S. and Ay, P., (2004)., Influence of polymer adsorption and conformation on flocculation and dewatering of kaolin suspension, Separat. Puri. Technol., 37, 231-246.

Delgado, S., Diaz, F., Garcia, D. and Oterto, N., (2003)., Behavior of inorganic coagulants in secondary effluents from conventional wastewater treatment plant, Separat. Filter., 40, 43-46.

Duan, J. and Gregory, J., (2003)., Coagulation by hydrolyzing metal salts, Advances in Colloid and Interface Science, 100, 475-502.
Exall, N. K. and Vanloon, W. G., (2003)., Effects of raw water conditions on solution-state aluminum speciation during coagulant dilution, Water Research, 37, 3341-3380.

Heimer, I. H., (2004)., Kirk-Othmer encyclopedia of chemical technology, John Wiley \& Sons, New York, 11, 488-517.

Kan, C., Haung, C. and Pan, R. J., (2002)., Time requirement for rapid-mixing in coagulation, Colloids and Surfaces, 203, 1-9.

Larsson, A., Walldal, C. and Wall, S., (1999)., Flocculation of Cationic polymers and nanosized particles, Coll. Surfac., 159, 65-76.

Liu, S. and liang, T., (2004)., Return sludge employed in enhancement of color removal in the integrally industrial wastewater treatment plant, Wat. Research, 38, 103-110.

Mccurdy, K., Carlson, K. and Gregory, D., (2004)., Floc morphology and cyclic shearing recovery: comparison of alum and polyaluminum chloride coagulants, Wat. Research., 38, 103-110.

McKetta, J. J., (2004)., Encyclopedia of chemical processing and design, $5^{\text {th }}$ ed., John Wiley, New York, 22. 


\section{AUTHOR(S) BIOSKETCHES}

Rahbar, M. S., Ph.D., is a assistant professor in the Department of Chemical Engineering, Imam Hussein University, Tehran, Iran. E-mail: msmnani@mail.ihu.ac.ir

Alipour, E., Ph.D., is a professor in the Department of Chemistry, Islamic Azad University, North Tehran Branch ,Tehran, Iran. E-mail:ej_alipour@yahoo.com

Eskandary Sedighi, R., M.Sc. student in applied chemistry, Islamic Azad University, North Tehran Branch ,Tehran, Iran

\section{This article should be referenced as follows:}

Rahbar, M. S., Alipour, E. and Sedighi R. E., (2006). Color removal from industrial wastewater with a novel coagulant-flocculant formulation. Int. J. Environ. Sci. Tech., 3 (1), 79-88. 